\title{
Measurement and Modeling of Particle Radiation in Coal Flames
}

Backstrom, Daniel; Johansson, Robert; Andersson, Klas Jerker; Johnsson, Filip; Clausen, Sønnik; Fateev, Alexander

\section{Published in:}

Energy \& Fuels

Link to article, DOI:

$10.1021 / \mathrm{ef} 402271 \mathrm{~g}$

Publication date:

2014

Document Version

Publisher's PDF, also known as Version of record

Link back to DTU Orbit

Citation (APA):

Backstrom, D., Johansson, R., Andersson, K. J., Johnsson, F., Clausen, S., \& Fateev, A. (2014). Measurement and Modeling of Particle Radiation in Coal Flames. Energy \& Fuels, 28(3), 2199-2210.

https://doi.org/10.1021/ef402271g

\section{General rights}

Copyright and moral rights for the publications made accessible in the public portal are retained by the authors and/or other copyright owners and it is a condition of accessing publications that users recognise and abide by the legal requirements associated with these rights.

- Users may download and print one copy of any publication from the public portal for the purpose of private study or research.

- You may not further distribute the material or use it for any profit-making activity or commercial gain

- You may freely distribute the URL identifying the publication in the public portal

If you believe that this document breaches copyright please contact us providing details, and we will remove access to the work immediately and investigate your claim. 


\title{
Measurement and Modeling of Particle Radiation in Coal Flames
}

\author{
Daniel Bäckström, ${ }^{* \dagger}{ }^{\dagger}$ Robert Johansson, ${ }^{\dagger}$ Klas Andersson $^{\dagger}{ }^{\circ}$ Filip Johnsson ${ }^{\dagger}$ Sønnik Clausen, $^{\dagger}$ \\ and Alexander Fateev ${ }^{\ddagger}$ \\ ${ }^{\dagger}$ Department of Energy and Environment, Chalmers University of Technology, SE-412 96 Göteborg, Sweden \\ "Department of Chemical and Biochemical Engineering, Technical University of Denmark (DTU), DK-2800 Kongens Lyngby, \\ Denmark
}

\section{Supporting Information}

ABSTRACT: This work aims at developing a methodology that can provide information of in-flame particle radiation in industrial-scale flames. The method is based on a combination of experimental and modeling work. The experiments have been performed in the high-temperature zone of a $77 \mathrm{~kW}_{\text {th }}$ swirling lignite flame. Spectral radiation, total radiative intensity, gas temperature, and gas composition were measured, and the radiative intensity in the furnace was modeled with an axisymmetric cylindrical radiation model using Mie theory for the particle properties and a statistical narrow-band model for the gas properties. The in-flame particle radiation was measured with a Fourier transform infrared (FTIR) spectrometer connected to a watercooled probe via fiber optics. In the cross-section of the flame investigated, the particles were found to be the dominating source of radiation. Apart from giving information about particle radiation and temperature, the methodology can also provide estimates of the amount of soot radiation and the maximum contribution from soot radiation compared to the total particle radiation. In the center position in the flame, the maximum contribution from soot radiation was estimated to be less than $40 \%$ of the particle radiation. As a validation of the methodology, the modeled total radiative intensity was compared to the total intensity measured with a narrow angle radiometer and the agreement in the results was good, supporting the validity of the used approach.

\section{INTRODUCTION}

Even though efforts are made to reduce the use of fossil fuels in electricity production, the global use of coal is continuously increasing. ${ }^{1}$ Pulverized combustion (PC) is the dominating technology for using coal for electricity production. In PC, the coal is milled to a size of $5-400 \mu \mathrm{m}$ and is fed to the furnace through a number of burners forming high-temperature flames. ${ }^{2}$ In the furnace, radiative heat transfer is the dominating heat-transfer mechanism. Particle radiation is the major contributor in the flame zone, ${ }^{3}$ but also the gaseous components contribute to the radiative heat transfer.

Gas radiation is characterized by its strong spectral dependence; gases absorb and emit radiation in specific spectral regions. The gas radiation can be modeled with high-resolution spectral models with high accuracy. Particles do, in contrast to the gas, continuously emit and absorb radiation in the entire spectrum, and large particles, such as coal and ash, also scatter radiation. Although the spectral properties of particles show a less complex behavior than the gas, modeling of particle radiation implies other challenges because there are larger uncertainties in the radiative properties of particles than those of gases. To characterize particle radiation, it is necessary to determine the particle temperature. Also, the amount of particles in the flame and the type of particles, fuel, soot, or ash, are important factors that depend upon coal type and combustion conditions. The present work focuses on methods to quantify these factors in coal flames by means of combining measurements and modeling.

There are several studies on measurements of particle temperatures in small lab-scale applications, e.g., in entrained flow reactors ${ }^{4-8}$ and drop-tube furnaces. ${ }^{9-11}$ These lab-scale measurements often give detailed information on the temperature evolution during combustion of single fuel particles. However, this work aims at using methods applicable to studies of radiative heat transfer in flames of pilot up to industrial size, i.e., conditions in which the lab-scale methods are difficult to implement. Measurements of the particle temperature in these large-scale flames are more scarce because of the complex measurement environment, especially with respect to the limited optical access, but some measurements have been performed in industrial-scale flames and in flames with combustion conditions similar to large-scale flames. ${ }^{12-16}$ Two-color pyrometry is the prevailing technique to measure the particle temperature, and it was first demonstrated in flame applications by Ayling and Smith $^{6}$ and has been used extensively since then, in both lab-scale $\mathrm{e}^{4,6,17}$ and larger flames. ${ }^{13,16}$ Two-color pyrometry uses two wavelengths in the visible spectral region to calculate the particle temperature. Other techniques, using three wavelengths, called multi-color pyrometry, also exist. ${ }^{18,19}$ The influence from soot and coal particles with different temperatures in two-color pyrometry was investigated by Grosshandler. ${ }^{20}$ It was concluded that the choice of wavelength is important and that the infrared (IR) region might be more accurate to use than the visible region if large temperature differences between soot and coal particles are expected. An alternative technique is to use a Fourier transform infrared (FTIR) spectrometer to measure in the IR spectral region from which the particle temperature can be

Received: November 19, 2013

Revised: January 24, 2014

Published: February 5, 2014 
estimated. Solomon et al. ${ }^{7}$ used the FTIR technique to measure particle temperatures in lab-scale applications, and since then, several groups have used similar approaches to measure particle radiation from flames. ${ }^{14,15,21}$ The problem with line-of-sight techniques, such as two-color pyrometry and spectroscopic techniques, is that the measured particle temperature becomes an average of the optical path for which the measurement is carried out. To overcome this problem, Butler et al. ${ }^{12}$ used a water-cooled probe with a cooled background to reduce the optical path, which enabled particle temperature measurements with a higher spatial resolution. Clausen et al. ${ }^{22}$ and Bak and Clausen ${ }^{14}$ developed a FTIR-based technique by connecting a water-cooled probe to a FTIR spectrometer via fiber optics, thus enabling in situ spectroscopic radiation measurements with a higher spatial resolution. Other temperature measurement techniques also exist, such as laser-based techniques, which can be used with good results in small-scale applications, especially for soot measurements. ${ }^{23}$ However, in large flames, laser techniques suffer from beam attenuation, limited optical access, vibrations, etc. and are rarely used in practical applications. ${ }^{24}$

In addition to the temperature of the particles, the particle load and the properties of the particles, i.e., the type of particles present in the flame, are important for the understanding of radiative heat transfer in coal flames. In the extensive experimental work in the controlled profile reactor at Brigham Young University, measurements of the particle temperature, particle number density, particle size, and radiative heat flux were carried out. ${ }^{13}$ In addition to the measurements, Mietheory-based particle modeling was performed to calculate the radiative heat flux in the reactor with the discrete ordinates method. ${ }^{12}$ A comprehensive data set for the measured flames was presented, but because two-color pyrometry was used, it was not possible to separate soot from coal/char or ash radiation and the soot volume fraction could not be measured with the equipment used. All of the tar in the coal was instead assumed to form soot, and from that assumption, the soot volume fraction was estimated. In the work by Stimpson et al., line-of-sight measurements of the soot volume fraction were performed with a two-color laser extinction method. ${ }^{25}$ The soot formation in coal-fired air- and oxy-fuel flames of similar scale as the flame in this work was investigated, and it was shown that the formation of soot was highly dependent upon the combustion conditions. Solomon et al. ${ }^{21}$ used a FTIR spectrometer to measure radiation from a small lab-scale coal flame. The contributions from coal/char particles and soot were separated on the basis of simplified assumptions on the spectral behavior of coal and soot. The results from the study by Solomon et al. suffer from the line-of-sight problem, which means that all measured properties are an average across the flame. Rego-Barcena et al. ${ }^{15}$ used a grating spectrometer to measure the emitted radiation from an industrial-scale flame. The emissivity and particle and gas temperatures were estimated from the measured spectra, but the data in this study are also based on line-of-sight measurements.

The present work combines experiments and modeling as a methodology to characterize particle radiation in a coal flame in Chalmers $100 \mathrm{~kW}$ oxy-fuel test rig. The work is a continuation of the work performed both at Chalmers ${ }^{3,26-28}$ and Risø $\mathrm{DTU}^{8,14}$ and has the aim to quantify particle temperatures and the type of particle radiation in the investigated flame. The experimental work includes measurements of spectrally resolved radiation, total radiative intensity, gas temperature, and gas composition. The radiation modeling is based on particle properties calculated with the Mie theory and gas properties calculated with a statistical narrow-band model. The spectrally resolved radiation is measured with a FTIR-based probe technique, ${ }^{14}$ which provides simultaneous estimation of the particle temperature and the amount of particles present in the flame. The use of the probe technique gives a spatial resolution along the cross-section. The temporal resolution of the measurement technique also enables information of fluctuations in both particle temperature and concentration. The measurement results are used in combination with modeling to compare the contributions from particles and gas on the total radiative heat transfer. The contributions from different types of particles are evaluated in the modeling, and an estimation of the amount of soot radiation is given. The modeled total (gas and particle) radiation is compared to measurements of the total intensity for validation of the methodology.

\section{METHODOLOGY}

FTIR-based measurements of spectral radiative intensity were performed in a cross-section of the high-temperature zone of a swirling coal flame. Total radiative intensity, gas composition, and gas temperature were also measured. The particle radiation, in terms of emissivity and particle temperature, for 13 positions along the diameter of the furnace was estimated from the spectral measurements, and the amount of particles corresponding to this radiation was obtained by Mie theory calculations. The data given by the experiments, particle load, particle temperature, gas composition, and gas temperature, were used as input to model the total radiative intensity in the cross-section of the furnace. The modeled results are finally compared to the measured total radiative intensity.

2.1. Experiments. The experiments were performed in the Chalmers $100 \mathrm{~kW}$ oxy-fuel test rig (although only air-fired experiments were conducted in the present work). The test rig is a refractory-lined, cylindrical furnace with a swirl burner mounted in the top. The fuel is added in a concentric tube with two air registers outside. The primary air has a swirl angle of $45^{\circ}$, and the secondary air has a swirl angle of $15^{\circ}$; the swirl number of the two registers are 0.79 and 0.21 , respectively. Details on the unit can be found elsewhere. ${ }^{3,29}$ The data in this work is from a $77 \mathrm{~kW}_{\text {th }}$ air-fired lignite flame with an air/fuel ratio of 1.18; the properties of the Lausitz lignite are shown in Table 1.

Table 1. Properties of the Coal (as Received)

$\begin{array}{lr}\text { moisture (wt \%) } & 9.5 \\ \text { ash (wt \%) } & 5.0 \\ \text { volatiles (wt \%) } & 50.0 \\ \text { fixed carbon (wt \%) (calculated) } & 35.5 \\ \text { net calorific value }(\mathrm{MJ} / \mathrm{kg}) & 21.3\end{array}$

The lignite is pre-dried and milled to an average diameter of $40 \mu \mathrm{m}$; details on the fuel and ash are presented by Fleig et al. ${ }^{30}$ All measurements were performed in the high-temperature zone of the flame, $384 \mathrm{~mm}$ from the burner. Total radiation intensity, spectral intensity, temperature, and gas composition profiles were measured by traversing the water-cooled probes radially through the furnace.

The gas temperature was measured with a water-cooled suction pyrometer equipped with a S-type thermocouple protected by three ceramic radiation shields. The in-flame gas was extracted with a watercooled extraction probe, and the gas was analyzed in a standard gas analyzing system and with a FTIR gas analyzer. A narrow angle radiometer of IFRF type (Figure 1) was used to measure the line-ofsight radiative total intensity with a quartz window as the background. A small purge gas flow of argon was used in the collimating tube to prevent particles and flue gas entering the probe. The line-of sight radiation is focused on the sensor, a thermopile, with a focusing lens, 


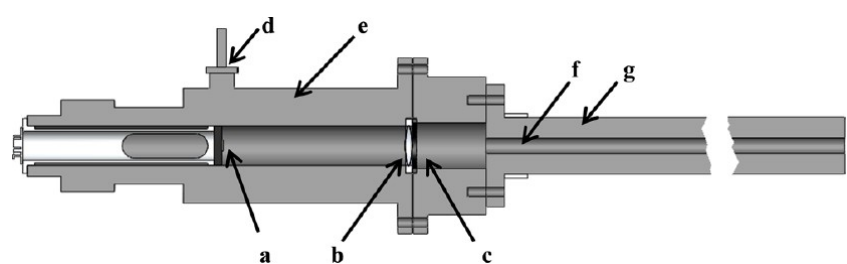

Figure 1. Schematic of the narrow angle radiometer, which was used to measure the total radiation intensity. The probe includes the following components: (a) thermopile, (b) focusing lens, (c) shutter, (d) PT-100, (e) water-cooled sensor housing, (f) collimating tube, and (g) water-cooled probe.

and the sensor housing is kept at a constant temperature by a separate water-cooling circuit.

The system used to measure the spectrally resolved radiation intensity from which the particle radiation is estimated is based on a design described by Bak and Clausen. ${ }^{14}$ It consists of a FTIR spectrometer, Bomem MB155, with an InSb detector cooled with liquid nitrogen and a fiber optic cable connected to the emission port of the spectrometer. The spectral resolution of the spectrometer is chosen to be $2 \mathrm{~cm}^{-1}$, and the spectral region covered by the $\mathrm{InSb}$ detector is $1700-7900 \mathrm{~cm}^{-1}$. To be able to carry out local in situ measurements, a water-cooled probe is used. The end of the fiber optic cable is positioned in the tip of the water-cooled probe, and a lens is focusing the radiation from the hot flue gas and particles onto a fiber optic link connected to the fiber optic cable (Figure 2). The optics is

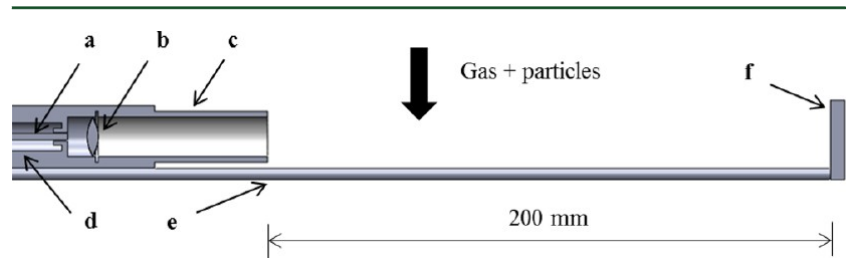

Figure 2. Cross-section of the tip of the optical probe: (a) fiber optic cable, (b) focusing lens, (c) ceramic protection tube, (d) water-cooled steel probe, (e) cooling water tube, and (f) water-cooled background.

protected by an uncooled ceramic tube and a small purge gas flow of argon. To have a known optical path length, a water-cooled beam stop is used. The optical path length was $200 \mathrm{~mm}$, and this distance was used when characterizing the radiation emitted by the particles over the distance between the beam stop and the ceramic tube.

To obtain the spectra from the measured signal, a two-point calibration was applied, ${ }^{31}$ with one point being a blackbody at high temperature and the other being at room temperature. The calibration procedure scales the measured spectra, so that the true spectral intensity is obtained. From the measured spectra, it is possible to calculate the gas temperature, particle radiation, and gas concentrations. ${ }^{14}$ In this work, only the particle radiation is considered, whereas the gas concentrations used in the modeling are taken from the extractive measurements.

2.2. Calculation of Emissivity and Particle Temperature from Measured Spectra. A common assumption is that coal particles are gray body emitters, which means that their emissivity shows no spectral dependence. Figure 3 a shows the absorption efficiency of coal and ash particles calculated with Mie theory in the spectral region of particular interest for this study. The complex index of refraction of the coal particles is based on data presented by Foster and Howarth, ${ }^{32}$ and the particle diameter is $40 \mu \mathrm{m}$. The complex index of refraction of the ash particles is taken from refs $33-35$, as presented in ref 27 , and the diameter is assumed to be $10 \mu \mathrm{m}$. The diameters of the coal and ash particles are based on data presented by Fleig et al. ${ }^{30}$ Figure $3 \mathrm{~b}$ shows the absorption coefficient of small soot particles calculated from Rayleigh theory according to Modest, ${ }^{36}$ with the complex index of refraction taken from eqs $19 \mathrm{a}$ and $19 \mathrm{~b}$ in the work by Chang and Charalampopoulos. ${ }^{37}$ As seen in the figure, the absorption efficiency of the coal particles is almost constant in the spectral region investigated. The absorption efficiency of the ash particles varies up to $15 \%$ but is on average also relatively constant. This means that it is reasonable to approximate the coal and ash particles as gray body emitters. However, the soot particles show a stronger spectral dependence and cannot be assumed gray without introducing errors in the calculations.

A typical spectrum from the FTIR measurements in the flame is shown in Figure 4a. The measured spectrum consists of radiation emitted by both flue gas and particles. To estimate the amount of particle radiation, a gray body Planck curve representing the particle radiation can be fitted to the spectral regions without gas radiation. The regions chosen for this study to determine the particle radiation from the $200 \mathrm{~mm}$ optical path are shown as shaded areas in Figure 4a. The signal-to-noise ratio is high in the two regions, around 2600 and $4200 \mathrm{~cm}^{-1}$ (panels b and $\mathrm{c}$ of Figure 4). If a longer optical path length is used and, thus, an increased signal, the spectral region around 6000 $\mathrm{cm}^{-1}$ can also be used. In this study, this region is excluded because of too poor of a signal-to-noise ratio. A least-squares fitting was used to find the gray body Planck curve best corresponding to the measured spectra in the regions around 2600 and $4200 \mathrm{~cm}^{-1}$. The two parameters used in the curve fit are particle temperature and emissivity. The particle temperature obtained is not a direct measure of the temperature of individual particles but represents an average of all particles in the $200 \mathrm{~mm}$ optical path. If the particle temperature is non-uniform along the path, the resulting temperature is likely biased toward the higher temperatures. ${ }^{38,39}$ The emissivity found from the gray body fit represents the amount of particles in the optical path. The emissivity fitted to the measured spectra was used to determine the particle load in the $200 \mathrm{~mm}$ optical path, as described in the next
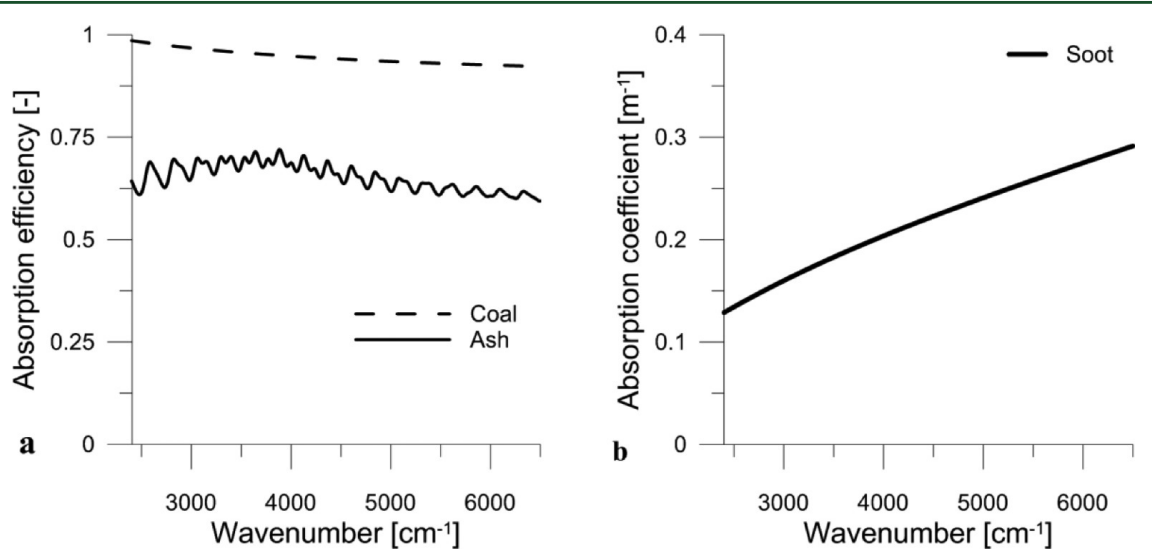

Figure 3. (a) Absorption efficiency of coal, $40 \mu \mathrm{m}$, and ash particles, $10 \mu \mathrm{m}$, calculated with Mie theory and (b) absorption coefficient for a soot volume fraction of $1 \times 10^{-7}$. 

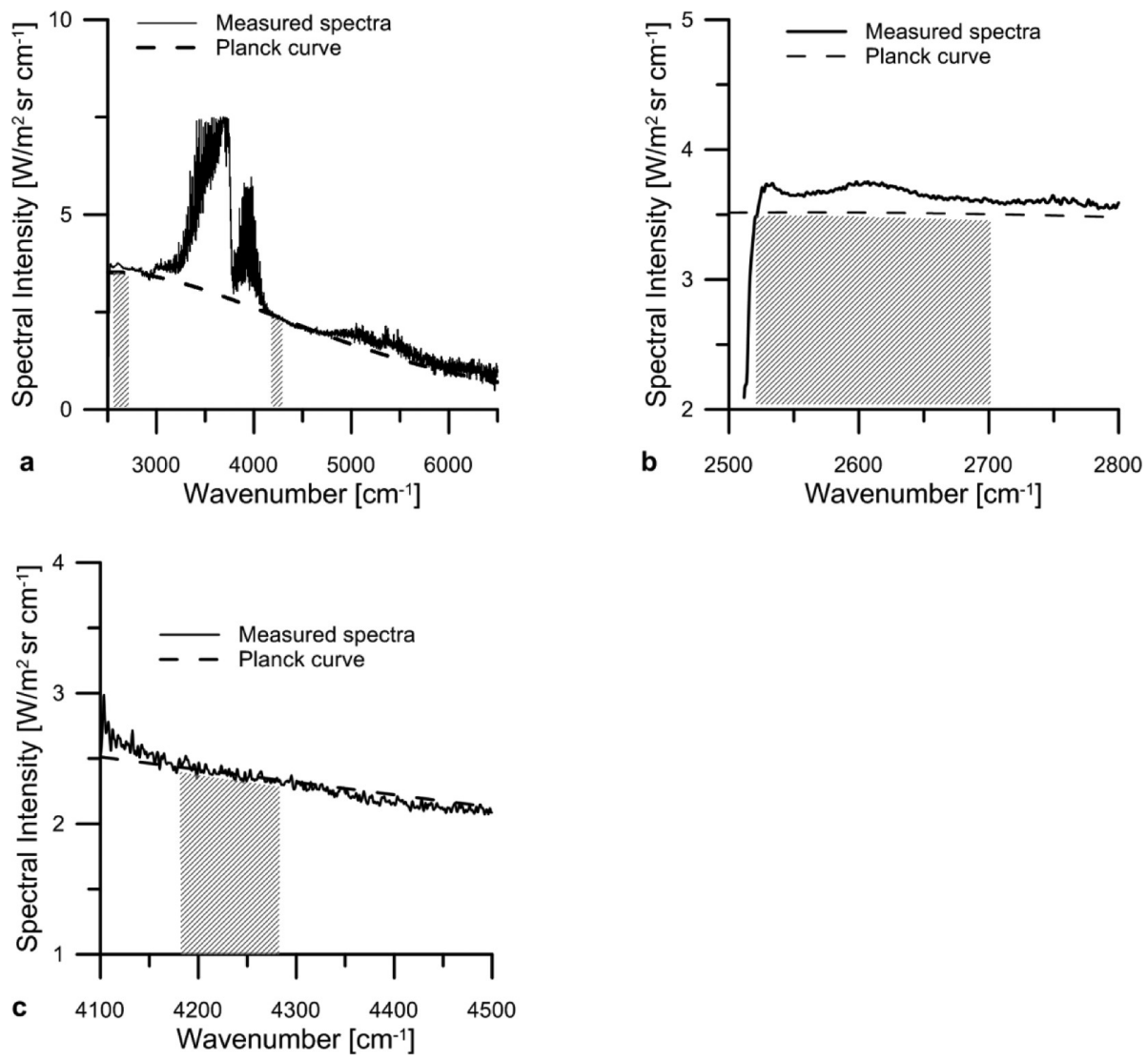

Figure 4. Measured spectra and fitted gray body radiation. (a) Areas used (shaded) when fitting the gray body to the measured spectra. (b and c) Close-ups of the areas of interest.

a

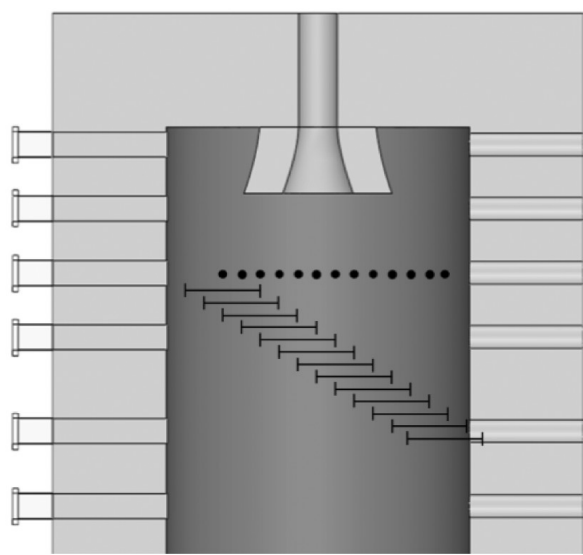

b

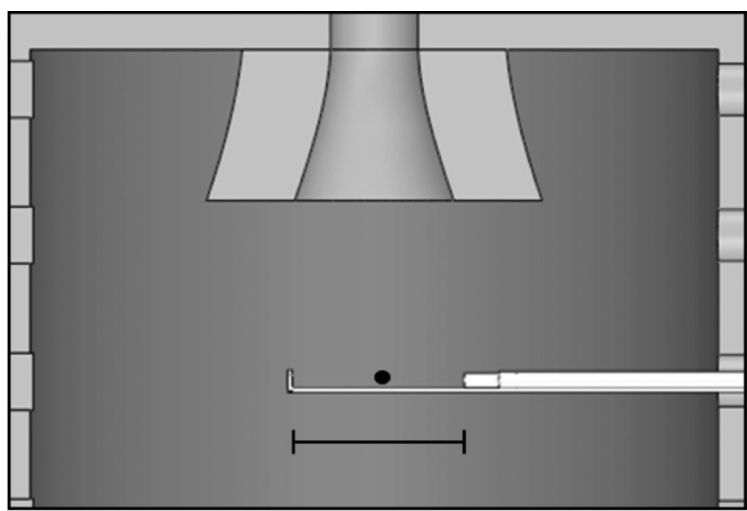

Figure 5. Top section of the combustion chamber. (a) Positions, indicated by dots, for measurements with the optical probe. The bars show the overlap between each $200 \mathrm{~mm}$ optical path. The bars are displayed with a horizontal displacement to illustrate the overlap between the measurement positions. (b) Optical probe during measurement in the center position. The optical path length is indicated as the line below the probe.

section. The uncertainty in the fitting of the gray body temperature and emissivity was evaluated in a sensitivity analysis.

2.3. Determination of the Amount of Particles. The particles in the center of the flame were assumed to be coal particles with a diameter of $40 \mu \mathrm{m}$. The particles outside the flame, in the recirculation zone, were assumed to be ash particles with a diameter of $10 \mu \mathrm{m}$. The positions with significantly lower temperature and emissivity were considered as recirculation zones and, thus, only containing ash particles. The influence from the choice of position when changing from coal to ash particles is evaluated in a sensitivity analysis, where the particles are assumed to be coal particles also in the recirculation zone. The particle load profile was determined by comparing modeled total particle radiation with total radiation calculated from the particle temperature and emissivity obtained from the FTIR spectra in each of the measurement positions. The projected surface area of all particles in the measurement volume was used as the fitting parameter. The modeled particle radiation in each of the $200 \mathrm{~mm}$ long measurement volumes was calculated assuming a uniform temperature and particle load in the volumes, with the particle properties calculated from the Mie theory. To account for scattering of radiation into the measurement volume, the radiative intensity field based on the modeling presented in section 2.4 was used. The intensity field and particle load profile across the furnace were iteratively calculated, and the solutions converged after a few iterations. The complex index of refraction of the particles is the same as the ones presented above. 

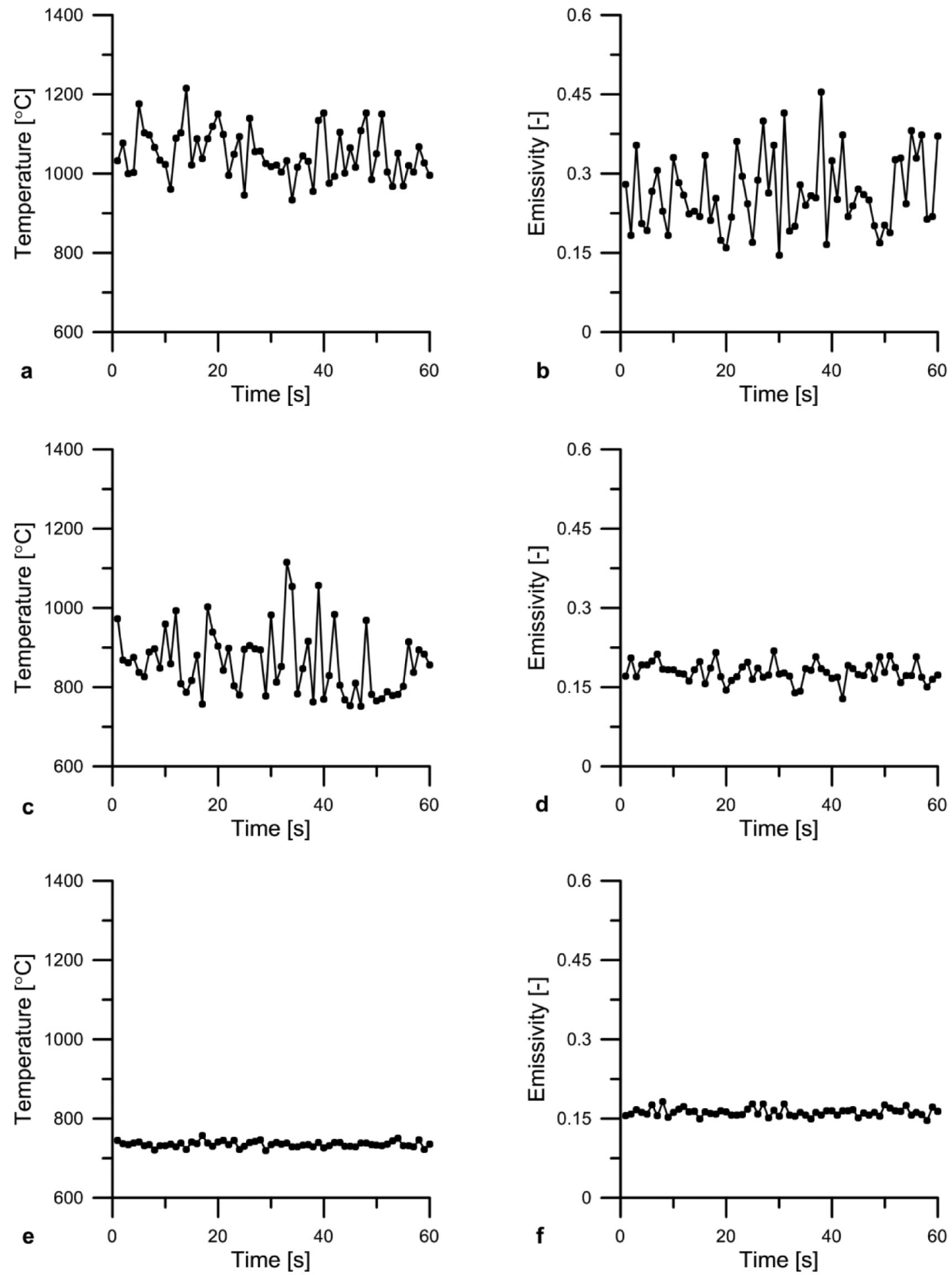

Figure 6. Example of the fitted gray body temperature and emissivity for $60 \mathrm{~s}$ with a sampling frequency of $1 \mathrm{~Hz}$. Particle temperature and emissivity are shown $(a$ and $b)$ in the center position, $(c$ and $d)$ in the flame boundary, and (e and $f$ ) in the recirculation zone close to the wall.

A projected surface area was calculated for each available spectrum in each measurement position, 13 positions and 60 spectra per position along the diameter of the reactor. Then, an arithmetic mean of the projected particle area in each position was calculated. The measurement positions are shown in Figure 5a, and the overlap between each $200 \mathrm{~mm}$ optical path can also be seen in the figure. Figure $5 \mathrm{~b}$ shows the optical probe in the center position of the reactor; the center position of the $200 \mathrm{~mm}$ optical path, represented by a dot, is used to define the position of the optical measurements.

It is not possible to completely distinguish between coal and soot radiation in the flame, and some of the particle radiation in the flame core stem from soot. To investigate the influence of soot particles on the predicted particle temperature, a sensitivity analysis was performed. For the soot particles, which are significantly smaller than the coal particles, Rayleigh theory was used. In the sensitivity analysis, the particles in the flame were assumed to be non-gray soot particles, with the complex index of refraction taken from ref 37 . Different soot temperatures and volume fractions are tested to investigate the influence from soot from which the maximum contribution of soot radiation to the particle radiation is estimated.

2.4. Modeling of Radiation. The change in radiation intensity along a line of sight in an absorbing, emitting, and scattering medium is described by the radiative transfer equation (RTE).

$$
\begin{aligned}
\frac{\mathrm{d} l_{v}}{\mathrm{~d} s}= & \kappa_{\mathrm{g}} I_{\mathrm{b}, v}\left(T_{\mathrm{g}}\right)+\kappa_{\mathrm{p}} I_{\mathrm{b}, v}\left(T_{\mathrm{p}}\right)-\left(\kappa_{\mathrm{g}}+\kappa_{\mathrm{p}}\right) I_{v}+\sigma_{v} I_{v} \\
& +\frac{\sigma_{v}}{4 \pi} \int_{0}^{4 \pi} I_{v}\left(\tilde{s}_{i}\right) \Phi\left(\tilde{s}, \tilde{s}_{i}\right) \mathrm{d} \Omega_{i}
\end{aligned}
$$

The first and second terms on the right-hand side in the RTE are the positive contributions from emission of radiation from gas and particles, respectively. The third term accounts for the decrease in intensity because of absorption of radiation by gas and particles. The fourth term represents the loss of radiation because of scattering of radiation into other directions. To calculate the last term in the RTE, which accounts for the positive contribution of in-scattered radiation 

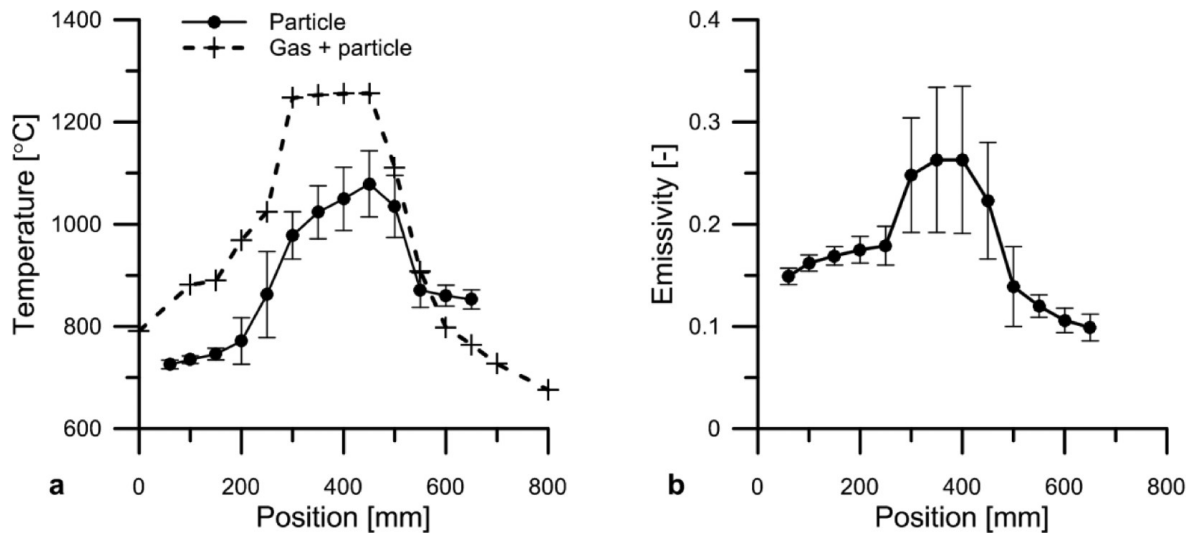

Figure 7. (a) Temperature profile in a cross-section of the furnace $384 \mathrm{~mm}$ from the burner. ( $)$ Particle temperature estimated from the optical probe measurements and $(+)$ gas and particle temperatures measured with the suction pyrometer. (b) Emissivity of the particles in the 200 mm measurement path of the optical probe.

from all other directions, the intensity in all directions in the furnace has to be known. The radiation intensity field in the Chalmers oxy-fuel test rig was calculated with a model presented by Johansson et al., 27,28 in which the geometry of the furnace is approximated as an infinitely long axisymmetric cylinder. The discrete transfer method was used to calculate the intensity. For details on the geometry and the implementation of the models, see refs 27 and 28 .

2.4.1. Gas Radiation. The measured temperature and concentration of $\mathrm{H}_{2} \mathrm{O}$ and $\mathrm{CO}_{2}$ in the cross-section of the flame were used as input in the modeling. The gas radiative properties were calculated with the Malkmus statistical narrow-band model. ${ }^{40}$ The narrow-band parameters were taken from the work by Soufiani and Taine. ${ }^{41}$ The total gas transmissivity in each narrow band, $k$, was calculated as the product of the transmissivity of $\mathrm{H}_{2} \mathrm{O}$ and $\mathrm{CO}_{2}$ (eq 2), and the CurtisGodson approximation was used for inhomogeneous paths.

$$
\bar{\tau}_{k, \mathrm{~g}}=\bar{\tau}_{k, \mathrm{H}_{2} \mathrm{O}} \bar{\tau}_{k, \mathrm{CO}_{2}}
$$

2.4.2. Particle Radiation. The particle temperature and projected particle area calculated from the optical probe measurements were used as input for the modeling of the particle radiation. Radiative properties of the particles were calculated according to the Mie theory with a complex index of refraction and particle properties, as described above for each narrow band of the gas radiation model, 150-9300 $\mathrm{cm}^{-1}$, as well as additional bands, $9300-17000 \mathrm{~cm}^{-1}$, also covering the visible spectral region. The transmissivities of the particles in each band were calculated as

$$
\bar{\tau}_{k, \mathrm{p}}=\exp \left(-\left(\sigma_{\mathrm{scat}, k, \mathrm{p}}+\kappa_{\mathrm{abs}, k, \mathrm{p}}\right) l\right)
$$

The total transmissivity of the particle gas mixture was obtained as the product of the transmissivity of the gas and the particles as

$$
\bar{\tau}_{k, \text { tot }}=\bar{\tau}_{k, \mathrm{~g}} \bar{\tau}_{k, \mathrm{p}}
$$

2.4.3. RTE with Different Gas and Particle Temperatures. The solution of the RTE follows the procedure presented in refs 27 and 28, with the difference that the model was modified to enable different particle and gas temperatures. The correlated solution of the RTE (eq 5) was used to calculate the intensity of each band. The derivation of eq 5 is given in the Supporting Information, and the indices used refer to a path discretized according to Figure A1, also presented in the Supporting Information.

$$
\begin{aligned}
\bar{I}_{v_{k}, n}= & \bar{I}_{v_{k}, 0} \bar{\tau}_{v_{k}, 0 \rightarrow n}+\sum_{i}\left(\left(1-\bar{\omega}_{v_{k}, i+1 / 2}-\bar{\Psi}_{v_{k}, i+1 / 2}\right) \bar{I}_{\mathrm{b}_{k}, i+1 / 2}\left(T_{\mathrm{g}}\right)\right. \\
& \left.+\bar{\Psi}_{v_{k}, i+1 / 2} \bar{I}_{\mathrm{b} v_{k}, i+1 / 2}\left(T_{\mathrm{p}}\right)+\bar{\omega}_{v_{k}, i+1 / 2} G_{\mathrm{scat}, i+1 / 2}\right) \\
& \left(\bar{\tau}_{v_{k}, i+1 \rightarrow n}-\bar{\tau}_{v_{k}, i \rightarrow n}\right)
\end{aligned}
$$

$$
\bar{\Psi}_{v_{k}}=\frac{\kappa_{v_{k}, \text { coal }}+\kappa_{v_{k}, \text { ash }}}{\beta_{v_{k}, \text { coal }}+\beta_{v_{k}, \text { ash }}-\ln \left(\bar{\tau}_{v_{k}, \mathrm{~g}}\right) / \Delta s}
$$

The parameter $\bar{\psi}_{v_{k}}$ is a result of the different gas and particle temperatures and relates the absorption by the particles to the total absorption and scattering by gases and particles. Finally, the total intensity was calculated as the sum of the band intensities times the bandwidth.

$$
\bar{I}_{n}=\sum_{i} \Delta v_{k} \bar{I}_{v_{k}, n}
$$

\section{RESULTS AND DISCUSSION}

Spectral radiation measurements with the optical FTIR-based system were performed for $60 \mathrm{~s}$ in each position in the flame, and one spectrum was recorded each second. Figure 6 gives examples obtained from the fitting of the particle temperature and emissivity in three positions in the flame $384 \mathrm{~mm}$ from the burner. The positions are center position $(400 \mathrm{~mm})$ (panels a and $\mathrm{b}$ of Figure 6 ), the flame boundary where the highest temperature gradients are expected $(250 \mathrm{~mm})$ (panels $\mathrm{c}$ and $\mathrm{d}$ of Figure 6), and the recirculation zone close to the wall (100 $\mathrm{mm}$ ) (panels e and $\mathrm{f}$ of Figure 6). In general, the fluctuations of emissivity are higher compared to the fluctuations of the temperature, except in the recirculation zone, where both temperature and emissivity are relatively constant. The highest emissivity fluctuations are found in the flame core (Figure 6b). The emissivity depends upon the amount of particles in the optical path and the spectral properties of the particles. One reason for the fluctuating particle concentration is the gravimetric coal feeding system, which is not capable of maintaining a constant fuel flow. Another reason is the turbulent nature of the coal flame, which can be observed visually. The temperature fluctuations are higher in the flame boundary (Figure 6c) than in the center position (Figure 6a), which is expected because the largest temperature gradients are found in the flame boundary.

An arithmetic mean of the temperatures in each position in the flame was calculated giving a temperature profile across the furnace. The profile is compared to the temperature profile measured with the suction pyrometer shown in Figure 7a (position $0 \mathrm{~mm}$ is where the probe was inserted, and the opposite wall is located at $800 \mathrm{~mm}$ ). The temperature measured with the suction pyrometer is an average of both the gas and particle temperatures. The thermal inertia in the 

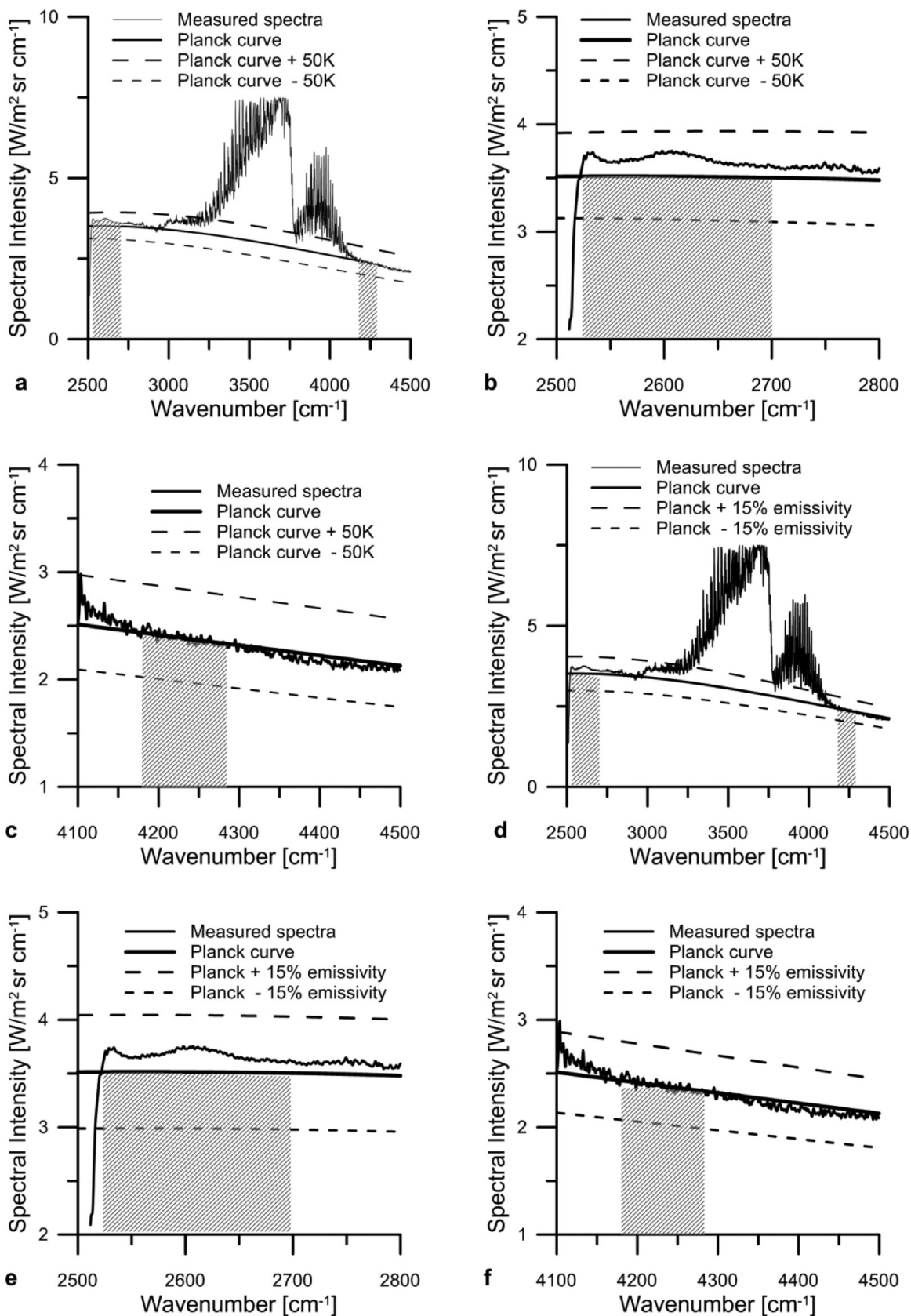

Figure 8. Sensitivity analysis of $(a-c)$ temperature and $(d-f)$ emissivity in the gray body fitting.

suction pyrometer prevents measurements of temperature fluctuations, whereas the optical technique provides an estimation of the fluctuations in both particle temperature and concentration. The fluctuations are illustrated in panels a and $\mathrm{b}$ of Figure 7 by error bars representing the standard deviation in each position. The maximum average particle temperature in this cross-section of the flame is around $200{ }^{\circ} \mathrm{C}$ lower than the maximum average gas temperature measured with the suction pyrometer. The particle temperature depends upon the particle type, size, and heating rate of the particles. These measurements were performed at a distance of $384 \mathrm{~mm}$ from the burner. The total length of the visible flame was around $1 \mathrm{~m}$, and it is likely that the conversion of the coal particles is still in the devolatilization phase in Figure 7 because of the short residence time from the burner to the position $(384 \mathrm{~mm})$, as indicated by the low temperatures. The non- symmetric particle temperature profile can be caused by reflections of radiation on the water-cooled background. Such reflections from the high-temperature flame could be important in the zones with a lower temperature but are not significant for measurements within the flame. Other explanations of the nonsymmetrical shape could be that the flame is not perfectly centered and disturbances induced by the probes.

Lafolletie et al. ${ }^{39}$ and Murphy and Shaddix ${ }^{38}$ both performed modeling studies of two-color pyrometry and investigated the influence of temperature gradients in the measurement volume. The results from these studies show that the measured temperature is biased toward the higher temperature in the measurement volume. For a $200 \mathrm{~mm}$ long measurement volume, this effect will cause an overestimation of the temperature in positions with large temperature gradients. Positions with significant temperature gradients are located at 

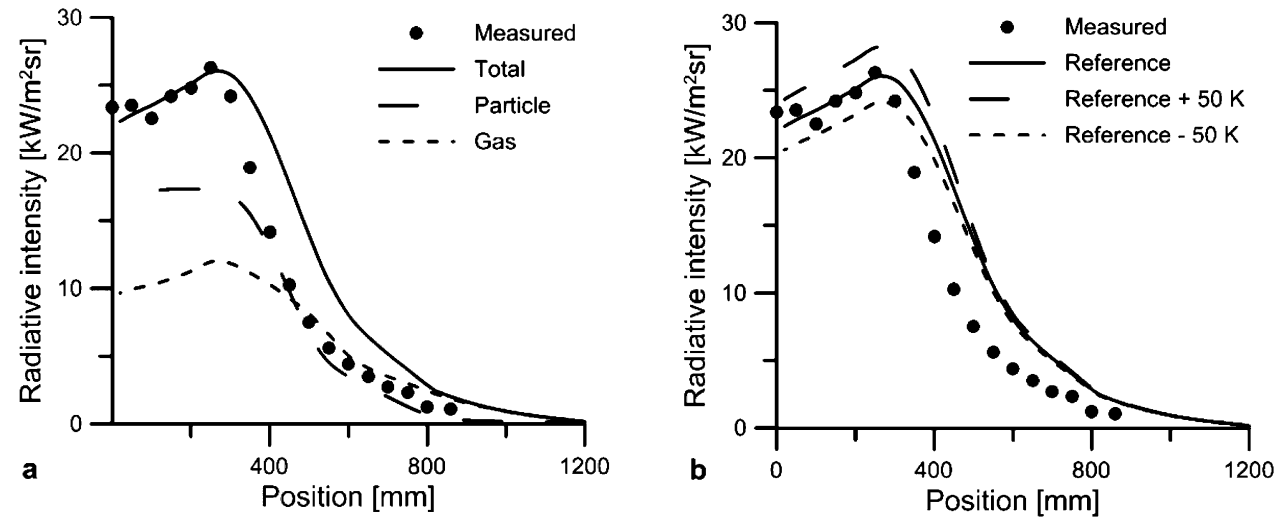

Figure 9. (a) Modeled and measured radiative intensity. (b) Sensitivity analysis of the particle temperature. The total intensity from panel a is used as a reference in panel $b$.

the flame boundaries. This will likely cause a temperature profile with a wider high-temperature zone than the true particle temperature profile. However, the suction pyrometer is also not a point measurement, and it is therefore not possible to measure large temperature gradients with this technique because of the high suction velocity, which must be applied in such a probe.

Figure $7 \mathrm{~b}$ shows the emissivity of the particles in the measurement volume found by the Planck curve fitting. The points represent the arithmetic mean of the 60 emissivities in each position, and the error bars show the standard deviation. Note that the emissivities shown represent the emissivity of all particles in the $200 \mathrm{~mm}$ long optical paths given in Figure 5a. The standard deviation is, as was also noted in Figure 6, significantly higher in the flame core, and this reflects the turbulent fluctuations in the flame and the uneven coal feeding. The standard deviation is lower in the region outside the flame. This region is a recirculation zone, which is expected to contain mainly ash particles. The flow pattern in this region is less turbulent, and no large differences in the particle concentration are expected, which is a likely reason for the lower standard deviation seen here.

Because the accuracy in the FTIR signal is high, the fitting of the Planck curve to the measured spectrum is a critical procedure with respect to the total accuracy of the results. To assess the accuracy in the fitting, a sensitivity analysis was therefore performed. Panels a-f of Figure 8 are examples of the sensitivity in the fitting of the gray body temperature and emissivity. In Figure 8a, the emissivity is constant and the particle temperature is increased and decreased by $50 \mathrm{~K}$. Panels $\mathrm{b}$ and $\mathrm{c}$ of Figure 8 show a magnification of the regions of interest in Figure 8a. As seen in panels b and $\mathrm{c}$ of Figure 8, with temperature differences larger than approximately $50 \mathrm{~K}$, the shape of the Planck curve is deviating from the measured curve and it is not possible to obtain the same agreement in all spectral areas of interest. In panels $\mathrm{d}-\mathrm{f}$ of Figure 8, the original emissivity is increased and decreased with $15 \%$. An increase in emissivity beyond $15 \%$ yields an increase in the intensity, which results in a poor fit of the curve in all spectral areas of interest. Combinations of these sensitivity analyses have also been performed, where input data of the opposite sign of temperature and emissivity were included (e.g., combining $+50 \mathrm{~K}$ and $-15 \%$ emissivity). These showed that the shape of the Planck curve is sensitive to a change in the temperature and it is not possible to achieve an accurate fitting with a significantly higher temperature and lower emissivity and vice versa. This means that it is likely that the temperature can be determined with an accuracy of approximately $\pm 50 \mathrm{~K}$, which corresponds to a relative uncertainty of around $\pm 4 \%$ in the center of the flame. The fitted emissivity is likely to be within $\pm 15 \%$.

Figure 9 shows the modeled and measured total radiation intensity above (Figure 9a) and the result of a sensitivity analysis with respect to the particle temperature (Figure 9b). The walls are located at 0 and $800 \mathrm{~mm}$, and the distance from 800 to $1200 \mathrm{~mm}$ represents the measurement port on the opposite side of the furnace from where the probe was inserted. The quartz window used as a cold background is located in the end of the measurement port at $1200 \mathrm{~mm}$. The gas concentrations used in the modeling are based on the extractive measurements and ranges between 9 and $11.6 \%$ for $\mathrm{H}_{2} \mathrm{O}$ and between 13.8 and $15.8 \%$ for $\mathrm{CO}_{2}$ in this cross-section. The $\mathrm{CO}$ concentration was $6 \%$ in the center position. The measured total radiative intensity is a result of the emitted, absorbed, and scattered radiation from the gas and particles in the line-of-sight path between the probe tip and the cold background. The gas and particle radiation were also modeled separately, and as seen from Figure 9a, the particle radiation is the dominant radiation source. The overall agreement between the measured and modeled total radiation is good, although the modeled profile is somewhat broader than the measured profile. This may be due to either uncertainties in the temperature profile or uncertainties in the amount of particles in the region close to the walls that was obtained from the FTIR measurements. Also, the signal-to-noise ratio of the detector in the narrow angle radiometer is poor when the intensity is low, as in the region when the probe end is close to the cold background, i.e., at distances within $600-800 \mathrm{~mm}$. When the results from this study are compared to earlier work performed in the same test rig, $3,27,28$ the overall agreement between measurements and modeling of the total radiative intensity is similar. The difference in this work compared to the previous work is that the particle load is based on a direct quantification of the particle radiation and not a fitting of the particle radiation to the measured total radiative intensity. The fact that the modeled total intensity agrees well with the measured intensity shows that the methodology presented in this work is capable of estimating the particle radiation in the investigated crosssection of the coal flame.

The sensitivity of the predicted particle temperature was examined by changing the particle temperature with $\pm 50 \mathrm{~K}$ in the cylindrical radiation model (Figure 9b). The figure shows 

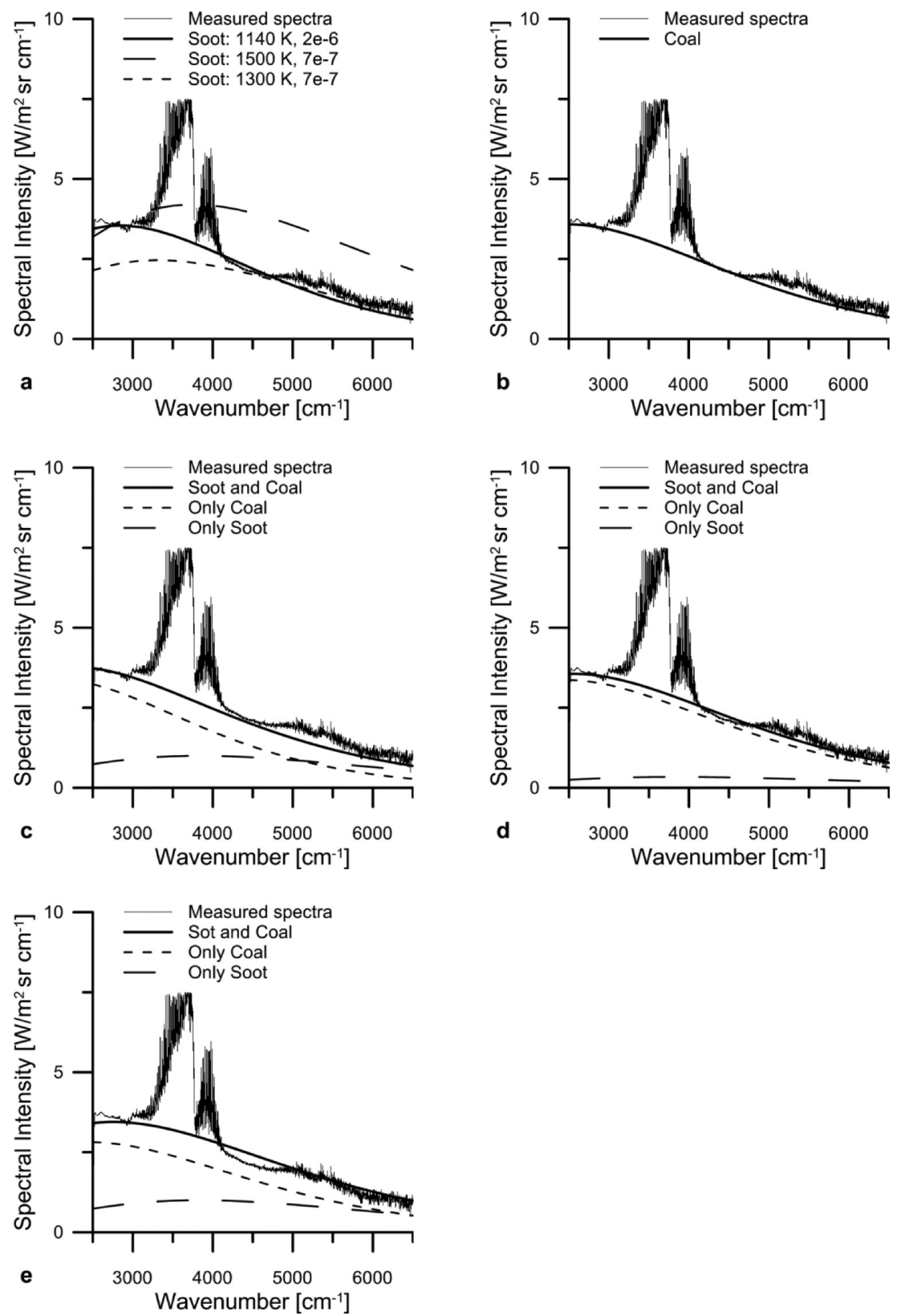

Figure 10. Examples of soot and coal radiation in the center position of the flame with cases according to Table 2: (a) case 1, varying soot temperature and soot load; (b) case 2, only coal particles; (c) case 3, with the coal particle temperature lower than in the reference case with only coal particles; (d) case 4, with a low soot volume fraction; and (e) case 5, with a higher soot volume fraction and coal particle properties as in case 2.

that the particle temperature is an important parameter in the radiation modeling, although the expected uncertainty in the predicted particle temperature (approximately $50 \mathrm{~K}$ ) does not significantly affect the results. In the fitting of the projected particle area, the positions with substantially lower measured spectral intensity, $0-250 \mathrm{~mm}$ from the walls, were assumed to contain only ash particles. The impact of having coal or ash particles is investigated using only coal particles in all positions. The difference in the result is negligible. Thus, the choice of particle type in the recirculation zone is not important for the modeling results. There is a discrepancy between the modeling and measurements in the region $350-800 \mathrm{~mm}$, and a likely part of the explanation for this is an overestimation of the amount of particles in the recirculation zone close to the walls. The spectral intensity in the positions in the recirculation zone is much lower than in the flame, and the signal-to-noise ratio is therefore lower, making the fitting procedure less accurate. Also, reflections from the water-cooled background may result in an overestimation of the amount of particles in this region because this effect has a stronger influence when the radiation emitted by the particles is low. However, for the parts of the flame where the particle radiation is higher, i.e., in the center of the flame, the signal is stronger and the predicted amount of particles is believed to be more accurate.

In the results presented above, the particles in the flame are assumed to be only coal particles. However, some studies, for example ref 16 , have shown that soot radiation is a main source for the particle radiation in the high-temperature flame zone. To investigate if small soot particles are also important in the lignite flame investigated, an extreme case was tested, where only small soot particles were used in the fitting of the particle temperature and particle load. Because small soot particles are 
Table 2. Different Particle Loads and Temperatures Tested $^{a}$

\begin{tabular}{|c|c|c|c|c|c|}
\hline & case 1 , Figure $10 a$ & case 2, Figure $10 \mathrm{~b}$ & case 3 , Figure $10 \mathrm{c}$ & case 4, Figure 10d & case 5 , Figure $10 \mathrm{e}$ \\
\hline$T_{\text {coal }}(\mathrm{K})$ & & 1300 & 1100 & 1300 & 1300 \\
\hline$f_{\mathrm{A}}\left(\mathrm{m}^{2} / \mathrm{m}^{3}\right)$ & & 1.7 & 2.95 & 1.6 & 1.3 \\
\hline$T_{\text {soot }}(\mathrm{K})$ & $1140,1300,1500$ & & 1500 & 1500 & 1500 \\
\hline$f_{\mathrm{v}}$ & $2 \times 10^{-6}, 7 \times 10^{-7}, 7 \times 10^{-7}$ & & $1.5 \times 10^{-7}$ & $0.5 \times 10^{-7}$ & $1.5 \times 10^{-7}$ \\
\hline share of soot radiation (\%) & 100 & 0 & 37 & 12 & 34 \\
\hline
\end{tabular}

${ }^{a_{1}}$ The average gas temperature measured with the suction pyrometer was $1500 \mathrm{~K}$ in the center position of the flame.

non-gray in the spectral area of interest, a non-gray model of the absorption coefficient based on the Rayleigh theory was used. $^{36}$ Figure 10a shows an example of the fitting of soot radiation to the measured spectrum. As shown in Figure 4a, it is possible to fit a gray body curve corresponding to a temperature of $1300 \mathrm{~K}$, which represents the particle radiation in this spectrum. Because the soot absorption is higher at higher wavenumbers (Figure $3 b$ ), a lower temperature of the soot is needed to obtain a shape of the curve similar to the gray body at $1300 \mathrm{~K}$. The best agreement of the fitting of soot was found for a temperature around $1140 \mathrm{~K}$ and a soot volume fraction of $2 \times 10^{-6}$. The average gas temperature in this position in the flame is approximately $1520 \mathrm{~K}$, and the soot temperature is thus unreasonably low. When the temperature is increased, the peak of the curve is shifted toward higher wavenumbers, and as Figure 10a shows, it is not possible to have a soot temperature close to the gas temperature and still maintain a good fit to the measured spectral intensity.

The soot temperature is expected to be at least as high as the gas temperature. To estimate the amount of soot that can be present without changing the shape of the particle radiation curve significantly, the influence of different amounts and temperatures of soot and coal particles was tested. Table 2 shows input values used in the cases investigated, and the resulting spectra are shown in panels a-e of Figure 10. Figure $10 \mathrm{~b}$ shows the reference case with coal particles. Because of the non-gray soot particles and also the higher temperature, including soot in the modeling has the tendency to shift the peak of the spectra toward higher wavenumbers. In Figure 10c, this effect from soot has been counter-acted by lowering the temperature and increasing the amount of the coal particles to maintain a similar fit as in the reference case (Figure 10b). The new coal particle temperature is $1100 \mathrm{~K}$, and the amount of coal particles is increased by $74 \%$. To which extent this low temperature reflects the true conditions in the flame is difficult to say, but, as noted before, the measurements are performed close to the burner and it is possible that the fuel particles have not had sufficient time to heat to the temperature of the surrounding gas. To quantify the soot contribution, the soot radiation and the combined soot and coal radiation were integrated and the ratio of these gives an approximation of the share of soot radiation in the total particle radiation. As seen from Table 2, this ratio is 0.37 for case 3 . Figure $10 \mathrm{~d}$ is an example of a case with a low soot volume fraction and the same coal temperature as in the gray body fit, $1300 \mathrm{~K}$. The agreement with the measured spectra is good for these conditions, but the share of soot radiation is lower, constituting $12 \%$ of the total particle radiation. Figure $10 \mathrm{e}$, case 5 , shows a spectrum with the same soot volume fraction and soot temperature as in Figure $10 c$, case 3 , but with a higher temperature and projected surface area of the coal. In this figure, the change in the shape of the curve is apparent and it is not possible to obtain an equally good fitting to all parts of the spectrum with only particle radiation. The results from this sensitivity analysis show that it is not possible to completely separate the contributions from coal and soot radiation. However, when the calculated combinations of coal and soot radiation are compared to the measured spectra, it is possible to obtain an estimation of the maximum amount of soot radiation that can be present in the flame without compromising the fitting or assuming unreasonable low coal particle temperatures. From the measurements in the center position in the flame, it is likely that the soot radiation constitutes a maximum of $40 \%$ of the total particle radiation. Cases 3-5 also indicate that the center of the flame has a soot volume fraction of around $1 \times 10^{-7}$. The estimated soot volume fraction in the coal flames investigated by Stimpson et al. ${ }^{25}$ ranged from 10 to $200 \times 10^{-9}$, a range that covers the maximum soot volume fraction estimated in this work.

The small contribution from soot radiation seen in this work compared to, for example, ref 16 might be explained by a low formation of soot in lignite flames. Seeker et al. ${ }^{17}$ and Fletcher et al. ${ }^{42}$ show that lignite does not produce as much soot as other coal ranks, such as bituminous coals. The picture in Figure 11 gives insight to the combustion condition in the investigated cross-section of the flame with respect to optical thickness and particle radiation.

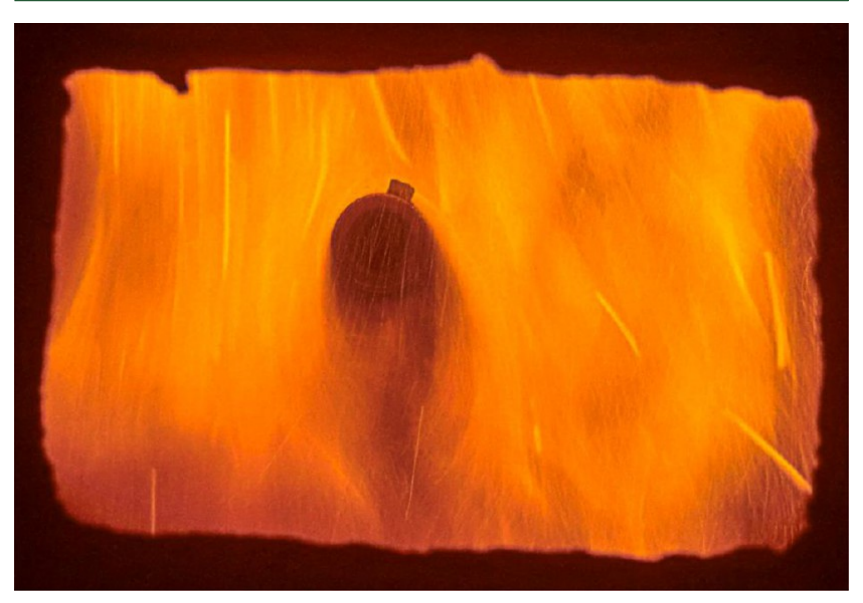

Figure 11. Picture of the coal flame during measurements with the optical probe without the water-cooled beamstop. The photo is taken through the quartz window, used as a cold background, at the opposite side from where the probe was inserted. In the photo, the probe tip is approximately in the center of the flame.

The results presented in this study are based on measurements in one cross-section of a specific coal-fired flame. The measurements were performed in the near burner region, which is believed to be the reason for the low particle temperatures observed. The amount of soot radiation estimated from the measured spectra is sensitive to the temperature of the coal 
particles. The information gained of the in-flame particle radiation is promising, and it would be useful to extend the measurements to cover more positions in the flame and to investigate other flame conditions. A broader variation of combustion conditions is planned to be investigated in future work.

\section{CONCLUSION}

The present work aims to provide a new methodology to study the particle radiation in coal flames. The method consists of a combination of experimental and modeling work. The experiments include measurements of spectrally resolved radiation, total radiative intensity, gas temperature, and gas composition. The radiation modeling is based on particle properties from the Mie theory and a statistical narrow-band model for the gas properties. The experimental work is based on measurements in a cross-section of the high-temperature zone near the burner of a swirling lignite-fired flame. The average particle temperature and emissivity for an optical path length of $200 \mathrm{~mm}$ was obtained from the spectrally resolved radiation measurements with an optical FTIR probe in 13 positions along the cross-section of the flame. The information obtained from the optical probe was used to find the corresponding projected surface area of the particles in the flame. The measured and calculated parameters were then used in a radiation model to calculate the radiative intensity in the cross-section of the flame, which was finally compared to the total radiative intensity measured with a narrow angle radiometer. The agreement was good, which demonstrates the potential of the presented methodology. It is found that, for the cross-section of the flame investigated in this work, the particle radiation is the dominating source of radiation. When calculations based on both soot and coal particles were compared, it was possible to estimate the contribution from soot on the total particle radiation. In the center position of the flame, it is concluded that soot radiation constitutes a maximum of $40 \%$ of the total particle radiation. The soot volume fraction is estimated to be in the order of $1 \times 10^{-7}$ in the same position.

\section{ASSOCIATED CONTENT}

\section{S Supporting Information}

Derivation of the solution of the RTE (eq 5) with different particle and gas temperatures. This material is available free of charge via the Internet at http://pubs.acs.org.

\section{AUTHOR INFORMATION}

\section{Corresponding Author}

*Telephone: +46-31-772-5257. E-mail: daniel.backstrom@ chalmers.se.

Notes

The authors declare no competing financial interest.

\section{ACKNOWLEDGMENTS}

The Swedish Energy Agency is gratefully acknowledged for financial support.

\section{NOMENCLATURE}

$$
\begin{aligned}
& f_{\mathrm{A}}=\text { projected surface area }\left(\mathrm{m}^{2} \mathrm{~m}^{-3}\right) \\
& f_{\mathrm{v}}=\text { soot volume fraction } \\
& G=\text { intensity integrated over all directions }\left(\mathrm{W} \mathrm{m}^{-2}\right) \\
& I=\text { total intensity }\left(\mathrm{W} \mathrm{m}^{-2} \mathrm{sr}^{-1}\right) \\
& l=\text { path length }(\mathrm{m})
\end{aligned}
$$

$$
\begin{aligned}
& s=\text { coordinate along a radiative path }(\mathrm{m}) \\
& \hat{s}=\text { unit vector in a given direction } \\
& T=\text { temperature }(\mathrm{K}) \\
& Y=\text { mole fraction }
\end{aligned}
$$

\section{Greek Letters}

$$
\begin{aligned}
& \beta=\text { extinction coefficient }\left(\mathrm{m}^{-1}\right) \\
& \gamma=\text { mean line half-width }\left(\mathrm{cm}^{-1}\right) \\
& \Delta s=\text { length of the computational cell }(\mathrm{m}) \\
& \varepsilon=\text { emissivity } \\
& \kappa=\text { absorption coefficient }\left(\mathrm{m}^{-1} \text { or bar } \mathrm{bm}^{-1}\right) \\
& \sigma=\text { scattering coefficient }\left(\mathrm{m}^{-1}\right) \\
& \tau=\text { transmissivity } \\
& \Phi=\text { scattering phase function }\left(\mathrm{sr}^{-1}\right) \\
& \Psi=\text { ratio between the particle absorption coefficient and the } \\
& \text { total extinction coefficient } \\
& \omega=\text { scattering albedo } \\
& \Omega=\text { solid angle }(\mathrm{sr})
\end{aligned}
$$

\section{Subscripts}

$0=$ wall, starting point of the radiative pathway

abs $=$ absorption

$\mathrm{b}=$ black body

$\mathrm{g}=$ gas

$i=$ cell number

$k=$ band $k$

$n=$ cell number

$\mathrm{p}=$ particle

scat $=$ scattering

tot $=$ total $($ gas + particle $)$

$v=$ spectral property

\section{REFERENCES}

(1) International Energy Agency (IEA). World Energy Outlook 2012; Organisation for Economic Co-operation and Development (OECD) Publishing: Paris, France, 2012.

(2) Williams, A.; Pourkashanian, M.; Jones, J. M. Combustion of pulverised coal and biomass. Prog. Energy Combust. Sci. 2001, 27 (6), 587-610.

(3) Andersson, K.; Johansson, R.; Hjärtstam, S.; Johnsson, F.; Leckner, B. Radiation intensity of lignite-fired oxy-fuel flames. Exp. Therm. Fluid Sci. 2008, 33 (1), 67-76.

(4) Niksa, S.; Mitchell, R. E.; Hencken, K. R.; Tichenor, D. A. Optically determined temperatures, sizes, and velocities of individual carbon particles under typical combustion conditions. Combust. Flame 1985, 60 (2), 183-193.

(5) Mitchell, R. E.; McLean, W. J. On the temperature and reaction rate of burning pulverized fuels. Symp. (Int.) Combust., [Proc.] 1982, 19 (1), 1113-1122.

(6) Ayling, A. B.; Smith, I. W. Measured temperatures of burning pulverized-fuel particles, and the nature of the primary reaction product. Combust. Flame 1972, 18 (2), 173-184.

(7) Solomon, P. R.; Carangelo, R. M.; Best, P. E.; Markham, J. R.; Hamblen, D. G. Analysis of particle emittance, composition, size and temperature by FT-i.r. emission/transmission spectroscopy. Fuel 1987, 66 (7), 897-908.

(8) Clausen, S.; Sørensen, L. H. Improved temperature measurements of burning char and coal particles using an FT-IR spectrometer. Energy Fuels 1996, 10 (5), 1133-1141.

(9) Timothy, L. D.; Sarofim, A. F.; Béer, J. M. Characteristics of single particle coal combustion. Symp. (Int.) Combust., [Proc.] 1982, 19 (1), 1123-1130.

(10) Khatami, R.; Stivers, C.; Levendis, Y. A. Ignition characteristics of single coal particles from three different ranks in $\mathrm{O}_{2} / \mathrm{N}_{2}$ and $\mathrm{O}_{2} /$ $\mathrm{CO}_{2}$ atm. Combust. Flame 2012, 159 (12), 3554-3568. 
(11) Khatami, R.; Levendis, Y. A. On the deduction of single coal particle combustion temperature from three-color optical pyrometry. Combust. Flame 2011, 158 (9), 1822-1836.

(12) Butler, B. W.; Denison, M. K.; Webb, B. W. Radiation heat transfer in a laboratory-scale, pulverized coal-fired reactor. Exp. Therm. Fluid Sci. 1994, 9 (1), 69-79.

(13) Tree, D. R.; Black, D. L.; Rigby, J. R.; McQuay, M. Q.; Webb, B. W. Experimental measurements in the BYU controlled profile reactor. Prog. Energy Combust. Sci. 1998, 24 (5), 355-383.

(14) Bak, J.; Clausen, S. FTIR emission spectroscopy methods and procedures for real time quantitative gas analysis in industrial environments. Meas. Sci. Technol. 2002, 13 (2), 150-156.

(15) Rego-Barcena, S.; Saari, R.; Mani, R.; El-Batroukh, S.; Thomson, $\mathrm{M}$. J. Real time, non-intrusive measurement of particle emissivity and gas temperature in coal-fired power plants. Meas. Sci. Technol. 2007, 18 (11), 3479-3488.

(16) Draper, T. S.; Zeltner, D.; Tree, D. R.; Xue, Y.; Tsiava, R. Twodimensional flame temperature and emissivity measurements of pulverized oxy-coal flames. Appl. Energy 2012, 95, 38-44.

(17) Seeker, W. R.; Samuelsen, G. S.; Heap, M. P.; Trolinger, J. D. The thermal decomposition of pulverized coal particles. Symp. (Int.) Combust., [Proc.] 1981, 18 (1), 1213-1226.

(18) Cashdollar, K. L. Three-wavelength pyrometer for measuring flame temperatures. Appl. Opt. 1979, 18 (15), 2595-2597.

(19) Levendis, Y. A.; Estrada, K. R.; Hottel, H. C. Development of multicolor pyrometers to monitor the transient response of burning carbonaceous particles. Rev. Sci. Instrum. 1992, 63 (7), 3608-3622.

(20) Grosshandler, W. L. The effect of soot on pyrometric measurements of coal particle temperature. Combust. Flame 1984, 55 (1), 59-71.

(21) Solomon, P. R.; Chien, P. L.; Carangelo, R. M.; Best, P. E.; Markham, J. R. Application of FT-IR emission/transmission (E/T) spectroscopy to study coal combustion phenomena. Symp. (Int.) Combust., [Proc.] 1989, 22 (1), 211-221.

(22) Clausen, S. Local measurement of gas temperature with an infrared fibre-optic probe. Meas. Sci. Technol. 1996, 7 (6), 888-896.

(23) Kohse-Höinghaus, K.; Barlow, R. S.; Aldén, M.; Wolfrum, J. Combustion at the focus: Laser diagnostics and control. Proc. Combust. Inst. 2005, 30 (1), 89-123.

(24) Nathan, G. J.; Kalt, P. A. M.; Alwahabi, Z. T.; Dally, B. B.; Medwell, P. R.; Chan, Q. N. Recent advances in the measurement of strongly radiating, turbulent reacting flows. Prog. Energy Combust. Sci. 2012, 38 (1), 41-61.

(25) Stimpson, C. K.; Fry, A.; Blanc, T.; Tree, D. R. Line of sight soot volume fraction measurements in air- and oxy-coal flames. Proc. Combust. Inst. 2013, 34 (2), 2885-2893.

(26) Andersson, K.; Johansson, R.; Johnsson, F.; Leckner, B. Radiation intensity of propane-fired oxy-fuel flames: Implications for soot formation. Energy Fuels 2008, 22 (3), 1535-1541.

(27) Johansson, R.; Andersson, K.; Johnsson, F. Influence of ash particles on radiative heat transfer in air and oxy-fired conditions. Proceedings of the Clean Coal Conference; Clearwater, FL, June 3-7, 2012.

(28) Johansson, R.; Leckner, B.; Andersson, K.; Johnsson, F. Influence of particle and gas radiation in oxy-fuel combustion. Int. J. Heat Mass Transfer 2013, 65 (0), 143-152.

(29) Hjärtstam, S.; Johansson, R.; Andersson, K.; Johnsson, F. Computational fluid dynamics modeling of oxy-fuel flames: The role of soot and gas radiation. Energy Fuels 2012, 26 (5), 2786-2797.

(30) Fleig, D.; Andersson, K.; Johnsson, F.; Leckner, B. Conversion of sulfur during pulverized oxy-coal combustion. Energy Fuels 2011, 25 (2), 647-655.

(31) Clausen, S.; Morgenstjerne, A.; Rathmann, O. Measurement of surface temperature and emissivity by a multitemperature method for Fourier-transform infrared spectrometers. Appl. Opt. 1996, 35 (28), $5683-5691$.

(32) Foster, P. J.; Howarth, C. R. Optical constants of carbons and coals in the infrared. Carbon 1968, 6 (5), 719-724, IN23, IN24, 725729.
(33) Lohi, A.; Wynnyckyj, J. R.; Rhodes, E. Spectral measurement of the complex refractive index of fly ashes of canadian lignite and subbituminous coals. Can. J. Chem. Eng. 1992, 70 (4), 751-758.

(34) Gupta, R. P.; Wall, T. F. The optical properties of fly ash in coal fired furnaces. Combust. Flame 1985, 61 (2), 145-151.

(35) Goodwin, D. G.; Mitchner, M. Flyash radiative properties and effects on radiative heat transfer in coal-fired systems. Int. J. Heat Mass Transfer 1989, 32 (4), 627-638.

(36) Modest, M. F. Radiative properties of particulate media. Radiative Heat Transfer, 2nd ed.; Academic Press: Burlington, MA, 2003; Chapter 11, pp 361-412.

(37) Chang, H.; Charalampopoulos, T. T. Determination of the wavelength dependence of refractive indices of flame soot. Proc. R. Soc. London, Ser. A 1990, 430 (1880), 577-591.

(38) Murphy, J. J.; Shaddix, C. R. Influence of scattering and probevolume heterogeneity on soot measurements using optical pyrometry. Combust. Flame 2005, 143 (1-2), 1-10.

(39) Lafolletie, R. M.; Hedman, P. O.; Smith, P. J. An analysis of coal particle temperature measurements with two-color optical pyrometers. Combust. Sci. Technol. 1989, 66 (1-3), 93-105.

(40) Malkmus, W. Random Lorentz band model with exponentialtailed $\mathrm{S}^{-1}$ line-intensity distribution function. J. Opt. Soc. Am. 1967, 57 (3), 323-329.

(41) Soufiani, A.; Taine, J. High temperature gas radiative property parameters of statistical narrow-band model for $\mathrm{H}_{2} \mathrm{O}, \mathrm{CO}_{2}$ and $\mathrm{CO}$, and correlated-K model for $\mathrm{H}_{2} \mathrm{O}$ and $\mathrm{CO}_{2}$. Int. J. Heat Mass Transfer 1997, 40 (4), 987-991.

(42) Fletcher, T. H.; Ma, J.; Rigby, J. R.; Brown, A. L.; Webb, B. W. Soot in coal combustion systems. Prog. Energy Combust. Sci. 1997, 23 (3), 283-301. 